\title{
Ambiances
}

anbiances Environnement sensible, architecture et espace urbain Comptes-rendus | 2013

L'explorateur sensible des villes

\section{Roger-Henri Guerrand. Corps et confort dans la ville moderne}

David Le Breton

\section{(2) OpenEdition}

Journals

Édition électronique

URL : http://journals.openedition.org/ambiances/159

DOI : 10.4000/ambiances. 159

ISSN : 2266-839X

Éditeur :

Direction Générale des Patrimoines - DAPA - MCC, UMR 1563 - Ambiances Architectures Urbanités (AAU)

\section{Référence électronique}

David Le Breton, «Roger-Henri Guerrand. Corps et confort dans la ville moderne », Ambiances [En ligne] Comptes-rendus, mis en ligne le 04 février 2013, consulté le 22 septembre 2020. URL : http:// journals.openedition.org/ambiances/159 ; DOI : https://doi.org/10.4000/ambiances.159

Ce document a été généré automatiquement le 22 septembre 2020.

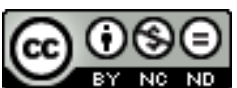

Ambiances is licensed under a Creative Commons Attribution-NonCommercial-NoDerivatives 4.0 International License. 


\title{
Roger-Henri Guerrand. Corps et confort dans la ville moderne
}

\author{
David Le Breton
}

\section{RÉFÉRENCE}

Guerrand, Roger-Henri. 2010. Corps et confort dans la ville moderne. Paris : Editions Recherches. 346 pages.

1 Roger-Henri Guerrand, né en 1923 est mort en 2006. Cet ouvrage est une série de textes rares ou inédits sous l'égide de Ginette Baty-Tornikian. On connait l'œuvre importante et foisonnante de Roger-Henri Guerrand, riche d'une quarantaine d'ouvrages et de nombreux articles.

2 Scout, militant du bureau national de la jeunesse étudiante chrétienne, il soutient une thèse mémorable sous la direction de Paul-Henry Chombart de Lauwe, elle sera publiée peu après : Les origines du logement social en France (1966) aux éditions ouvrières. Il est lu avec passion par les étudiants en architecture qui, en mai 68, écrivent dans un tract: «Il faut lire Lénine, Panofsky et Guerrand ». Historien de l'envers du décor, des petites choses de la vie, des objets dérisoires et intimes, il a notamment écrit sur Les lieux. Histoire des commodités (La Découverte, 1985 et 1997), sur le bidet : Le confident des dames. Le bidet du XVIII au XX siècle : histoire d'une intimité (La Découverte, 1997), le contrôle des naissances : Jeanne Humbert et la lutte pour le contrôle des naissances (Spartacus, 2001), l'art nouveau : L'art nouveau en Europe (1965). Il a souvent écrit sur le métro et son histoire, notamment son Histoire du métropolitain (La Découverte, 2000), sur le logement social, un fil rouge de son œuvre d'historien depuis la publication de sa thèse en 1966, jusqu'à plus récemment La modernité des HLM (La Découverte, 2003). En 2005, il publie son autobiographie à Infolio éditions: A contre-voie: mémoires de la vie sociale (1923-2000). Historien en effet des chemins de traverse, inclassable et d'une curiosité infinie, il trace son chemin propre entre Weber, les Annales et l'anthropologie d'un Mauss. Il enseigne à 
l'Ecole d'architecture de Paris. Pourtant il habitera longtemps dans l'une de ces cités HLM sur lesquelles il porte un regard de sociologue.

Corps et confort dans la ville moderne est une précieuse traversée de toute l'existence et l'œuvre de Guerrand à travers une myriade d'articles devenus introuvables, ou restés inédits. Cet ouvrage est une mine pour l'historien, le sociologue, l'anthropologue, l'architecte, l'urbaniste, mais aussi pour le flâneur, le curieux de toutes les dimensions de la vie quotidienne en milieu urbain. Les textes de Guerrand sont classés en différentes rubriques. "Les acteurs du bien-être» permettent de croiser des personnages l'ayant intéressé à un moment ou à un autre de son existence par leur action politique, littéraire ou autre : de Jules Verne à Hector Guimard, de Savorgnan de Brazza à l'abbé Pierre, en passant par le promoteur du « chemin de fer souterrain » qui allait devenir le métro, Fulgence Bienvenüe. Une autre section aborde différents aspects de la ville moderne que Guerrand a parfois plus longuement traités mais qui se trouve là à l'état de programme ou d'ébauches autour par exemple de l'art nouveau et des transports publics. D'autres textes abordent l'âge d'or des villes d'eau, Trouville, les vacances. Une troisième section s'attache aux « instruments du confort », on y lit une série de textes dans la veine la plus connue de Guerrand autour des logements sociaux, des HLM, de la salubrité ou des textes sur des objets de la vie quotidienne comme la machine à laver ou la barbotte (machine à laver dans laquelle le linge est brassé dans une lessive ou une eau savonneuse). Le dernier chapitre traite surtout du corps avec notamment un texte sur la masturbation, les avortements avant la première guerre mondiale ou la fraude sur les aliments.

4 Un compte rendu ne rend guère justice à la fécondité de cette pensée inclassable, dont on sent à la lecture la générosité, et qui ne cesse d'apprendre au lecteur sur les dimensions à la fois minuscules et essentielles de la vie commune.

\section{AUTEURS}

\section{DAVID LE BRETON}

David Le Breton est professeur de sociologie et anthropologie à l'Université de Strasbourg et membre du Laboratoire Cultures et Sociétés en Europe (CNRS - UdS)

david.le.breton@unistra.fr 